\title{
6
}

Oficina Económica y Comercial de España en Brasilia*

\section{IMPACTO DE LA PANDEMIA DE LA COVID-19 SOBRE LA ECONOMÍA BRASILEÑA}

La pandemia derivada de la COVID-19 está teniendo un impacto global del que la economía de la República Federativa de Brasil no ha sido ajena. La ya de por sí compleja gestión de esta pandemia alcanza otra dimensión cuando se trata de la quinta economía mundial por tamaño (diecisiete veces España) y población (212 millones de personas) con un sistema federal en el que los distintos niveles administrativos (Unión, estados y municipios) deben coordinarse. Analizar esta dimensión requiere un enfoque de análisis en tres esferas, política, sanitaria y económica, que serán abordadas en este artículo. Las medidas puestas en marcha por el Gobierno federal, para tratar de amortiguar los efectos que las medidas de aislamiento social necesarias para el control de la pandemia tienen sobre la actividad económica, han llevado a que el ejercicio 2020 cierre con un descenso del producto interior bruto (PIB) del 4,1\%, por debajo de los registros de otras economías de la región o de otras economías de la Organización para la Cooperación y el Desarrollo Económicos (OCDE). El cumplimiento de las perspectivas de una recuperación en forma de $\mathrm{V}$ con un crecimiento del entorno del 3,5\% para 2021 dependerán, en gran medida, de la velocidad de avance del proceso de vacunación de la población y de la recuperación de medidas de apoyo extinguidas a final de 2020 y que se tornan necesarias aún en el actual escenario, donde Brasil continúa inmerso en la segunda ola de la COVID y las medidas de aislamiento social siguen siendo necesarias para tratar de controlar la expansión del virus.

Palabras clave: COVID-19, crecimiento, recuperación, política económica, sanitaria, confianza. Clasificación JEL: E65, I18, O54.

\section{Introducción}

La expansión global del virus que causa la COVID-19, que fue considerada como situación de pandemia por la Organización Mundial de la Salud (OMS) el 11 de marzo de 2019, alcanza a

*Secretaría de Estado de Comercio. Este artículo ha sido elaborado por Isabel Rata, Consejera Económica y Comercial de España en Brasilia, con la colaboración de Jaime Levy Moreno, Analista de Mercado.

Versión de febrero 2021.

DOI: https:/doi.org/10.32796/bice.2021.3133.7167
18 de febrero de 2021 unas cifras próximas a los 111 millones de contagios confirmados en el mundo y casi 2,5 millones de fallecidos.

Esta pandemia no ha sido ajena a la República Federativa de Brasil (Brasil), quinto país del mundo en tamaño y población que, en el contexto de la pandemia, se sitúa el segundo del mundo por número de fallecimientos con más de 240.000 muertes acumuladas desde el inicio de la pandemia hasta el 18 de febrero, solo por detrás de Estados Unidos, y el $\triangleright$ 


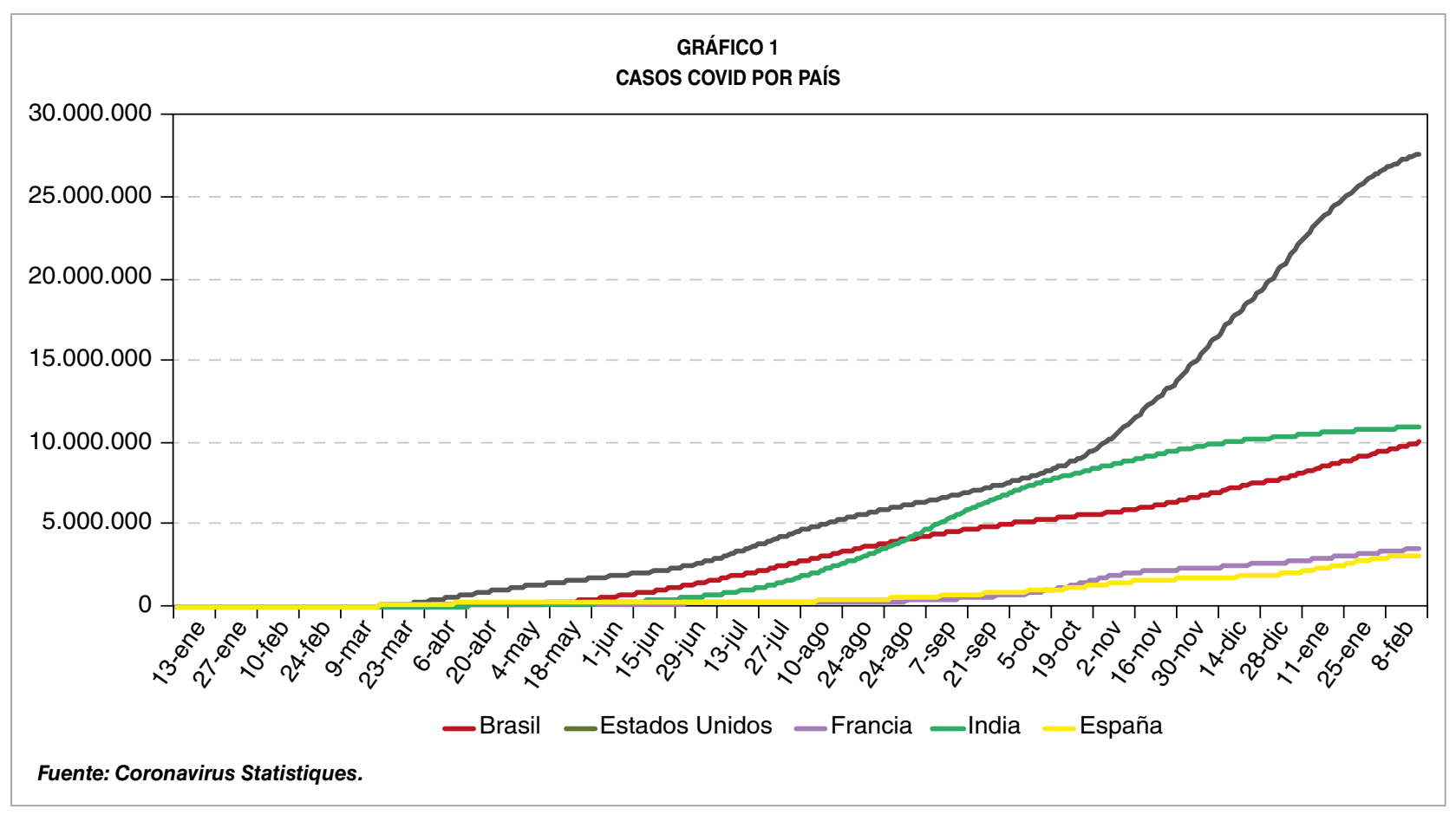

tercero por número de casos, con 10 millones de casos en el mismo periodo de comparación, tan solo por detrás de Estados Unidos e India. El Gráfico 1 recoge esta comparación sobre la base de información recopilada por Coronavirus Statistiques, a partir de las distintas fuentes oficiales, y del Instituto Johns Hopkins en su Centro de Recursos sobre Coronavirus para diversos países sensiblemente afectados por la pandemia.

Ante esta situación, los efectos sobre la sociedad y la economía brasileñas son innegables en tres áreas fundamentales: en la vertiente sanitaria, en la vertiente política y en la vertiente económica.

A lo largo del presente artículo se va a realizar una revisión de estos tres vectores que rigen, en la actualidad, las directrices de política económica y social del Gobierno brasileño, haciendo especial hincapié en la batería de medidas desarrolladas por el equipo económico para paliar los efectos sobre la economía del gigante iberoamericano.
Por tanto, el presente artículo seguirá el siguiente esquema: una introducción de los vectores salud, política y economía; un apartado por vector de su evolución y un apartado específico de las medidas eminentemente económicas que el Gobierno brasileño ha adoptado para contrarrestar los efectos de la pandemia de coronavirus sobre la población y sobre la economía nacional.

\section{Tres vectores: salud, política y economía}

A la hora de analizar el impacto de la pandemia derivada de la COVID-19 en Brasil es necesario analizar tres vectores que están interrelacionados entre sí y que no pueden dejar de evaluarse en conjunto: la evolución de la pandemia en sí, la gestión política de la crisis y el impacto de la pandemia sobre la economía brasileña.

Pero antes de comenzar, para entender la realidad actual de Brasil es necesario hacer $D$ 
una breve referencia a su estructura. Brasil es una república federal formada por veintiséis estados más el Distrito Federal, con un sistema de gobierno presidencialista en el que el presidente de la República es elegido por sufragio universal por un periodo de cuatro años, reelegible solo una vez. Dada su estructura federal y las grandes dimensiones de Brasil (es un país de tamaño continental, diecisiete veces España), los gobernadores son actores de primer rango e influencia, también a escala nacional, $y$, especialmente, los de grandes estados como São Paulo, Rio de Janeiro o Minas Gerais. Los alcaldes (prefeitos) de las principales ciudades tienen también un peso importante.

En los últimos años, el marco político de Brasil ha sufrido diversos sobresaltos, destacando el impeachment en 2016 de la presidenta Dilma Rousseff por haber infringido la Ley Presupuestaria y la inesperada victoria de Jair Bolsonaro en las elecciones de 2018, en un contexto en el que la corrupción del sistema político alcanzaba cotas nunca vistas tras el estallido del caso conocido como Lava Jato (y la multitud de operaciones derivadas de ella). A raíz de esta operación anticorrupción se desvelaba la implicación en sistemas criminales organizados de un gran número de políticos y empresarios brasileños, algunos de primerísimo nivel, como el propio expresidente Luiz Inácio Lula da Silva, el expresidente de la Cámara de los Diputados (Eduardo Cunha), el expresidente Temer o empresas brasileñas consideradas grandes líderes nacionales (Odebrecht, Andrade Gutierrez o el mega empresario brasileño Eike Batista, que llegó a ser el octavo hombre más rico del mundo según la revista Forbes en la etapa de los presidentes Lula da Silva y Dilma Rousseff).

Es en este contexto en el que hay que analizar los resultados de las elecciones de octubre de 2018, que dieron como resultado la victoria de Jair Bolsonaro, entonces afiliado al Partido Social Liberal (PSL) y que, actualmente, se encuentra sin partido. Durante su campaña electoral fue apoyado por las denominadas bancadas de las «tres bes» (con una representación muy relevante en el Congreso y el Senado): la bancada de la Biblia (en referencia a la Iglesia Evangélica), la de la bala (apoya la tenencia de armas como fórmula para reducir el crimen) y la del buey (en referencia al agronegocio).

En el centro de su programa de gobierno, Bolsonaro colocó como bandera de su agenda política la lucha contra la corrupción, dirigida por el juez Sergio Moro (conocido como el juez de la operación Lava Jato) como ministro de Seguridad Pública y Justicia y, en la vertiente económica, una agenda liberalizadora, marcadamente ortodoxa y a desarrollar por un superministro de Economía, Paulo Guedes, próximo a la escuela de Chicago. Guedes colocó, en primer lugar de esa agenda, culminar con la reforma de la Seguridad Social como elemento clave para recuperar el desequilibrio fiscal y sentar las bases de un crecimiento económico sólido y sostenido. Una vez conseguido ese objetivo, en el último trimestre de 2019 , al inicio de 2020 Guedes se propuso lanzar la reforma administrativa y la tributaria para avanzar en la modernización del Estado brasileño.

Sin embargo, la pandemia derivada de la COVID-19 y sus efectos devastadores sobre la población y la economía brasileñas requirieron frenar ese proceso de reformas temporalmente para hacer frente a los efectos de la misma.

\subsection{Vector sanitario}

Actualmente, la pandemia en Brasil se encuentra en la expansión de la segunda ola, con un total de 9.978 .747 casos confirmados a día $\square$ 
17 de febrero y 242.090 fallecidos, según los datos ofrecidos por el Ministerio de Salud brasileño.

Asimismo, se ha comenzado, el 17 de enero, la vacunación con más de 5,5 millones de dosis aplicadas a 18 de febrero de 2021, según el Consorcio de Medios de Comunicación (Consórcio de meios de comunicação ${ }^{1}$ ), lo que supone el $2,6 \%$ de la población brasileña.

Del proceso de expansión de la COVID-19 en Brasil hay que destacar varios elementos: (i) Brasil es como un continente, por lo que la expansión del virus no ha sido homogénea, se inició en São Paulo, en el sudeste del país y centro económico y financiero de Brasil, concentrando el mayor número de casos y fallecimientos por agrupar, además, el $21 \%$ del total de la población brasileña (44 millones de personas en el estado, aproximadamente como España) y se ha ido extendiendo a gran velocidad, primero por los estados costeros del sudoeste y nordeste (Río de Janeiro, Bahia, Pernambuco...) para luego ir expandiéndose por el interior, el norte del país y el sur. Actualmente, se está asistiendo a situaciones sanitarias críticas en la región del norte, debido a que la segunda ola y la aparición de una variante propia de Brasil (de Amazonas, en concreto) está atacando a poblaciones de partida muy pobres y muy azotadas y empobrecidas por la primera ola, de modo que estados como Amazonas o Rondonia, por ejemplo, se han visto obligados a derivar pacientes a otros estados ante el colapso del sistema de salud y han necesitado la ayuda de las fuerzas armadas brasileñas para hacer llegar y distribuir oxígeno a la población; (ii) además del tamaño del país, Brasil es una economía dual, con polos de desarrollo en los que existe más capacidad y recursos para gestionar

Esta plataforma está compuesta por los portales de las principales cadenas de medios: G1 y UOL y los periódicos O Globo, Extra, O Estado de S. Paulo y Folha de S. Paulo. la crisis sanitaria conviviendo con áreas mucho más pobres con menos recursos; (iii) la propia ordenación administrativa del país (Unión, estados y municipios) y los elevados niveles de autonomía de los entes subnacionales (estados y municipios) han dificultado una gestión coordinada de la crisis sanitaria, debido a la distribución de competencias sobre la materia entre los diferentes niveles administrativos y las diferencias políticas entre muchos de los dirigentes subnacionales y el Gobierno federal; (iv) las características anteriores (tamaño, desigualdad y distribución de competencias) hacen que la gestión de la pandemia haya sido especialmente compleja en Brasil. $Y$ esto ha tenido un impacto fuerte sobre el Gobierno federal y la economía, como se verá en los puntos siguientes.

\subsection{Vector político}

La evolución de la pandemia en Brasil no ha sido ajena a la gestión política y la valoración de su actual Gobierno.

El Gobierno Bolsonaro comenzó su andadura el 1 de enero de 2019 en un contexto de hastío político tras los escándalos de corrupción derivados de la operación Lava Jato y que alcanzó no solo a grandes empresarios «campeones nacionales», sino también a primeras espadas del imaginario político. En este contexto, Bolsonaro se alzó con la victoria con un amplio apoyo del electorado, dispuesto a reconducir al país hacia una senda de crecimiento económico sostenido y sin corrupción. De por sí, esto hace que el Gobierno Bolsonaro haya tenido desde el inicio una especial relación con la población, medida por su apoyo en medios y redes sociales, además de encuestas de opinión.

El estallido de la pandemia, a comienzos de 2020, modificó la estrategia de política y $\triangleright$ 
gestión económica prevista a inicios de año para el presidente brasileño. Si bien en un primer momento Brasil fue de los primeros países en aprobar una ley que dispone las principales medidas a adoptar para enfrentar la situación de emergencia sanitaria internacional derivada del brote de coronavirus, Ley 13.979, de 6 de febrero de $2020^{2}$, imponiendo, asimismo, el estado de emergencia sanitaria alineado con lo declarado por la OMS, la gravedad de la pandemia y su rápida expansión por un país continental comenzaron a generar una clara rivalidad entre el Gobierno federal y los estaduales (principalmente con los gobernadores de São Paulo y del Nordeste) en la manera de gestionar la crisis. Esta tensión se expandió incluso hacia el propio equipo de gobierno y se extendió también a la relación con la Cámara y el Senado y con los medios de comunicación.

Durante los primeros meses de pandemia, se asistió a continuos desencuentros políticos entre el presidente y los gobernadores — principalmente Doria (São Paulo), Witzel (Río de Janeiro) o Costa (Bahia)_, entre el presidente y su ministro de salud -entonces el médico de carrera Henrique Mandetta, que fue cesado en plena expansión de la COVID-19 por desavenencias en la manera de enfocar la pandemia-, entre el presidente y los presidentes del Congreso y el Senado —entonces Rodrigo Maia y Davi Alcolumbre-, y del presidente contra los medios de comunicación, que se saldó con un apagón informativo de una semana sobre los datos de la COVID-19 a principios de junio, en pleno pico, y que tuvo como reacción la creación, por parte de los medios de prensa, de una plataforma paralela de control de esa información: el Consorcio de meios de comunicação.

2 Lei $n . .913 .979$, de 6 de fevereiro de 2020, Dispõe sobre as medidas para enfrentamento da emergência de saúde pública de importância internacional decorrente do coronavírus responsável pelo surto de 2019.
La tensión fue máxima en mayo, momento en el que los asesores del presidente consiguieron reconducir la política de comunicación del mandatario y las tensiones consiguieron relajarse, dado el impacto que estas guerras políticas empezaban a tener en la valoración del presidente por parte de la población y en la opinión internacional. Hasta esa fecha ya se habían registrado desde el inicio de la pandemia el cese de dos ministros de salud (los médicos Henrique Mandetta y Nelson Teich) y uno de los ministros más destacados del Gobierno de Bolsonaro (Sergio Moro).

De hecho, en la encuesta de finales de mayo que periódicamente realiza el instituto de investigación social DataFolha se recogía que la desaprobación del Gobierno del presidente Jair Bolsonaro subía del $38 \%$ de finales de abril al $43 \%$, la tasa más alta desde el inicio de su gobierno. Asimismo, Bolsonaro decidió, el 10 de junio, recrear un ministerio, el de Comunicación, para reconducir su política de relación con el interior y el exterior.

Esta contención política se ha mantenido relativamente hasta la actualidad, si bien el presidente ha seguido protagonizando declaraciones que han dado la vuelta al mundo en relación con su valoración de la pandemia, sus efectos o la manera en la que hay que combatirla. Esto ha hecho, incluso, que la consecución de las vacunas para Brasil, a principios de 2021, haya requerido un ejercicio de extrema diplomacia, desarrollado no por el canciller brasileño — que ha alimentado muchas de las declaraciones de Bolsonaro consideradas desafortunadas por muchos-, sino por la ministra de Agricultura, Tereza Cristina, el secretario de Asuntos Estratégicos del Palacio de Planalto, el almirante Flavio Rocha, y el ministro de Comunicación, Fabio Faria.

Además, todo este proceso se ha vivido en un periodo de elecciones municipales $\square$ 
(previstas para octubre de 2020, finalmente retrasadas hasta noviembre) que han sido un primer test para Bolsonaro de cara a su próxima reelección, en las presidenciales de octubre de 2022. Y el resultado no ha sido tan positivo como esperaba el presidente, confiado tras la mejora de las encuestas de valoración de DataFolha y que en su publicación de la primera quincena de agosto arrojaban una mejora en la aprobación del Gobierno del presidente Jair Bolsonaro, del $32 \%$ alcanzado en la segunda quincena de junio al $37 \%$, su mejor tasa desde el inicio de su mandato. La desaprobación (suma de la mala y muy mala evaluación) cayó más drásticamente y pasó del $44 \%$ al $34 \%$ en el mismo periodo.

Ya comenzado el año 2021, el conflicto derivado de la gestión de la pandemia entre el gobernador Doria y el presidente Bolsonaro se ha reactivado tras las informaciones surgidas sobre la gestión de las vacunas así como por la negativa del presidente a recuperar el auxilio de emergencia, prorrogado en sucesivas ocasiones desde su establecimiento al inicio de la pandemia hasta su extinción el 31 de diciembre de 2020, medida ésta considerada como una de las estrellas en la batería desplegada por el equipo económico. En este marco, DataFolha publicaba, el 25 de enero de 2021, en su encuesta de valoración sobre el Gobierno Bolsonaro la menor tasa de aprobación del presidente desde el inicio de su mandato, un $31 \%$, frente a una reprobación del $40 \%$ (valoración mala o pésima). A continuación, el Gráfico 2 muestra la evolución, hasta finales de enero, de esa valoración de la gestión de Bolsonaro de la crisis derivada de la expansión de la pandemia.

Con las elecciones a la presidencia del Senado y la Cámara de diputados resueltas el 1 de febrero de 2021 a favor de los dos candidatos apoyados por Bolsonaro, Arthur Lira como presidente de la Cámara (del Partido Progresistas de Alagoas) y Rodrigo Pacheco como presidente del Senado (del Partido Demócratas de Minas Gerais), se espera que no prospere la multitud de solicitudes de impeachment contra Bolsonaro surgidas durante la gestión de la crisis de la COVID-19 y que se prioricen, en la agenda parlamentaria, las reformas retrasadas por la pandemia, principalmente de carácter económico, con los ojos puestos ya en las elecciones presidenciales de 2022.

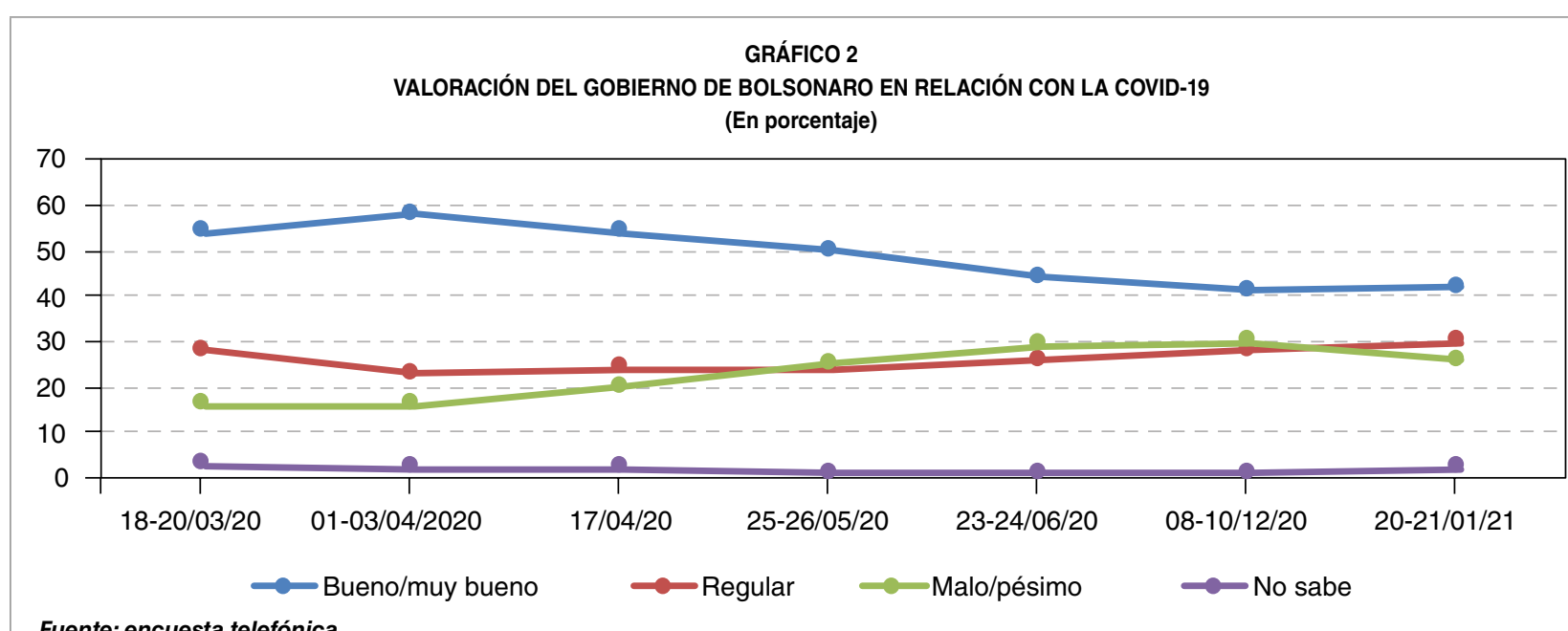

La encuesta telefónica empleada en este estudio representa el total de la población adulta del país. Se entrevistó a un total de 2.030 brasileños adultos, procedentes de todas las regiones y estados del país, siendo el margen de error de 2 puntos porcentuales. 


\subsection{Vector económico}

La mención a los dos vectores anteriores se hace necesaria para entender el impacto de la pandemia sobre la economía de Brasil.

Si bien no ha existido unanimidad y centralización en la toma de decisiones contra la COVID-19 - de manera que no se ha producido un cierre/ lock down del país-, los gobernadores de casi todos los estados ( $y$, desde luego, por parte de los de los estados más afectados) han tomado medidas de cierre de actividades no esenciales y recomendación de autoaislamiento, en el intento de frenar la expansión del virus y el colapso de sus sistemas sanitarios. También ha sido así para muchos alcaldes de multitud de municipios, que han decretado lock downs temporales en sus ciudades para tratar de contener el colapso del sistema sanitario a medida que aumentaban los casos, los internamientos y los fallecimientos.

Estas medidas fueron más habituales en las primeras semanas de expansión, alcanzando el peor momento en abril de 2020. De esta forma, los resultados de contabilidad nacional trimestral, publicados por el Instituto Brasileño de Geografía y Estadística (IGBE) para el periodo enero-marzo de 2020, mostraron ya un descenso intertrimestral del 2,1\%, la primera caída en trece trimestres (desde la crisis de 2015-2016). Y ya con los datos del segundo trimestre, periodo abril-junio, se confirmaba el peor resultado en toda la serie histórica al tener en cuenta el mes de abril, el peor mes de la crisis. Así, con datos corregidos de variaciones estacionales, el PIB brasileño cayó un 9,2\% intertrimestral entre abril y junio, siendo en términos interanuales la caída del $10,9 \%$.

En diciembre de 2020 se publicaban los datos de las cuentas nacionales trimestrales para el periodo julio-septiembre, arrojando un avance intertrimestral del PIB del 7,7\%, la mayor variación positiva de la serie histórica iniciada en 1996. En el último trimestre del año, el PIB ha continuado creciendo, en términos intertrimestrales, con un avance del 3,2\%. A pesar del crecimiento registrado, este ha sido insuficiente para compensar todavía los descensos de actividad anteriores, acumulando una contracción del $-4,1 \%$ en el conjunto del año, frente al año 2019.

EI Gráfico 3 recoge la evolución del PIB trimestral en los últimos casi treinta trimestres.

GRÁFICO 3

TASA DE VARIACIÓN DEL PIB INTERTRIMESTRAL

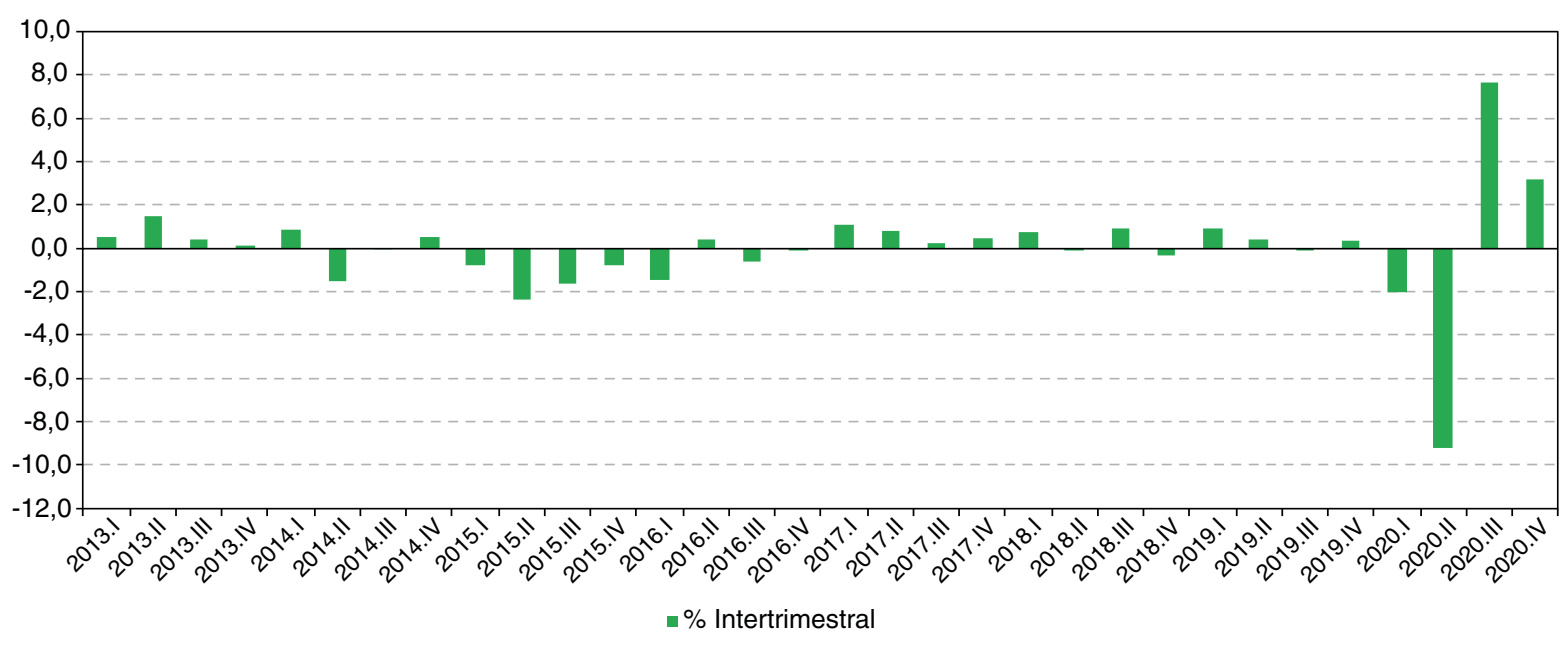

Fuente: IBGE. Sistema de Contas Nacionais Trimestrais. 
Las previsiones de crecimiento para 2020 eran optimistas al comienzo del ejercicio y se esperaba una aceleración que se reforzaría con el avance de las reformas pendientes. Sin embargo, el estallido de la pandemia al inicio del año ha llevado a un escenario completamente diferente, con continuas revisiones a la baja del crecimiento hasta esperar una caída del PIB del entorno del 5\% para el Gobierno brasileño, que otros organismos de previsión internacionales, como el Fondo Monetario Internacional o la OCDE, sitúan en el $-5,8 \%$ o el $-6 \%$, respectivamente.

No obstante, se estima que la evolución del PIB de Brasil sea en forma de V, esperando un avance del PIB en 2021 en el entorno del $3 \%$. El repunte sería menor que el esperado para otras economías del mundo, debido a que las medidas de apoyo económico llevadas a cabo por la Administración brasileña habrían conseguido amortiguar el impacto sobre la economía, siendo el descenso esperado para Brasil menor que el de otros países de su entorno y del de otras economías mundiales, y, análogamente, siendo el «rebote» esperado más suave.

A continuación se recoge, en los Gráficos 4, 5, 6 y 7, la evolución del PIB brasileño comparada con la de otros países, como Estados Unidos o la media de la OCDE, así como un indicador adelantado de la actividad elaborado por la OCDE (composite leading indicator), o los indicadores de confianza empresarial y de los consumidores de la OCDE.

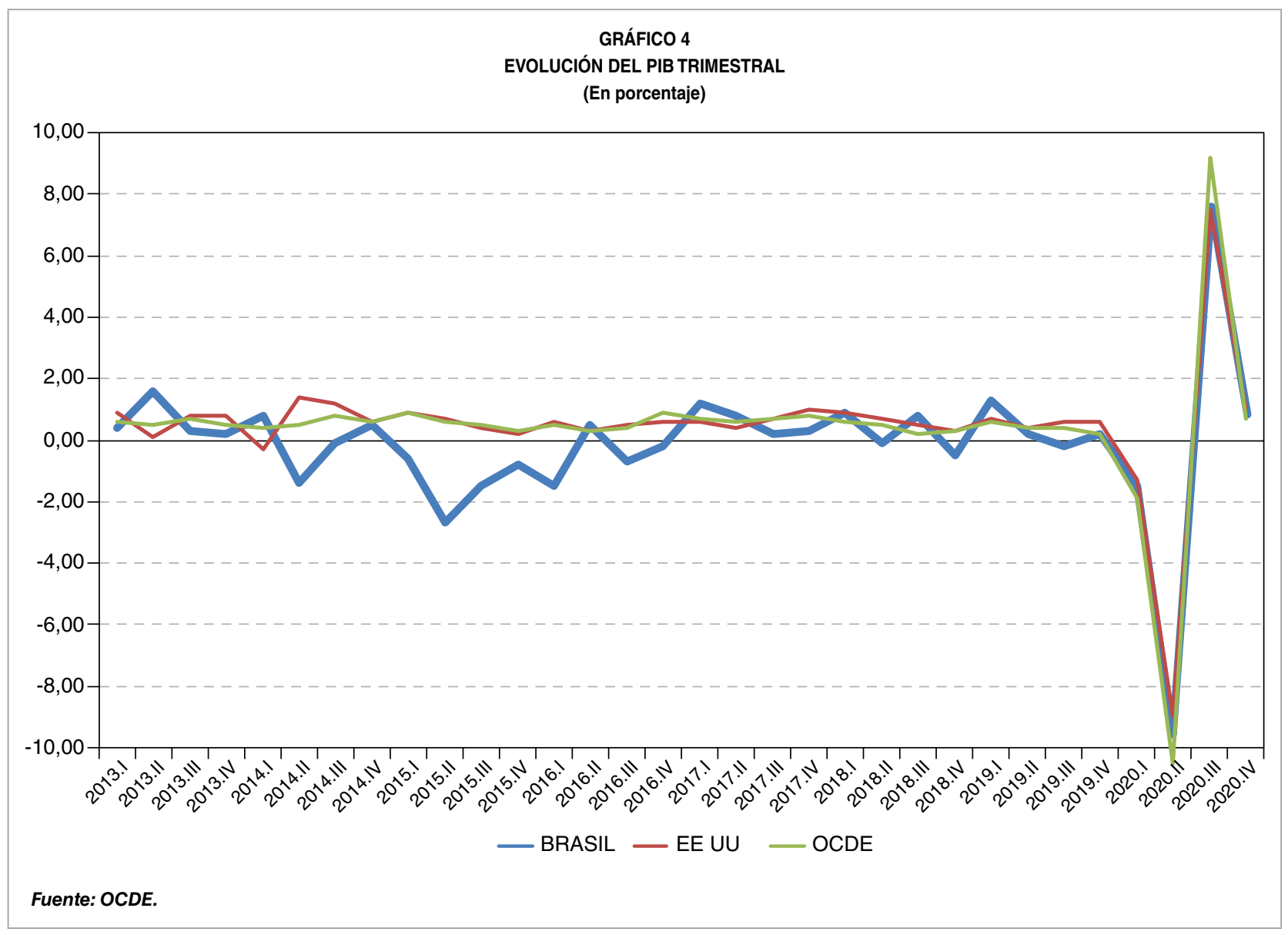


IMPACTO DE LA PANDEMIA DE LA COVID-19 SOBRE LA ECONOMÍA BRASILEÑA
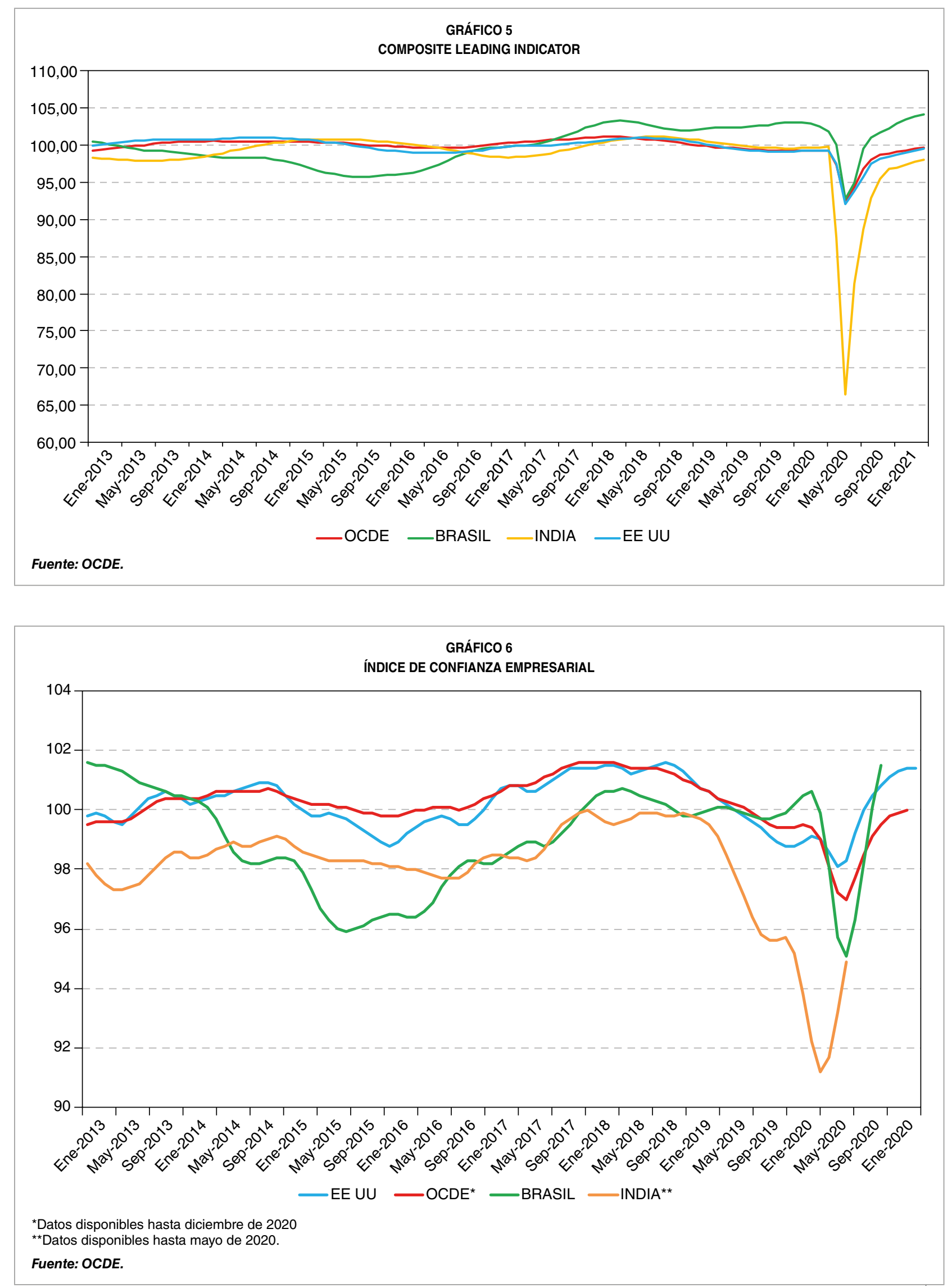


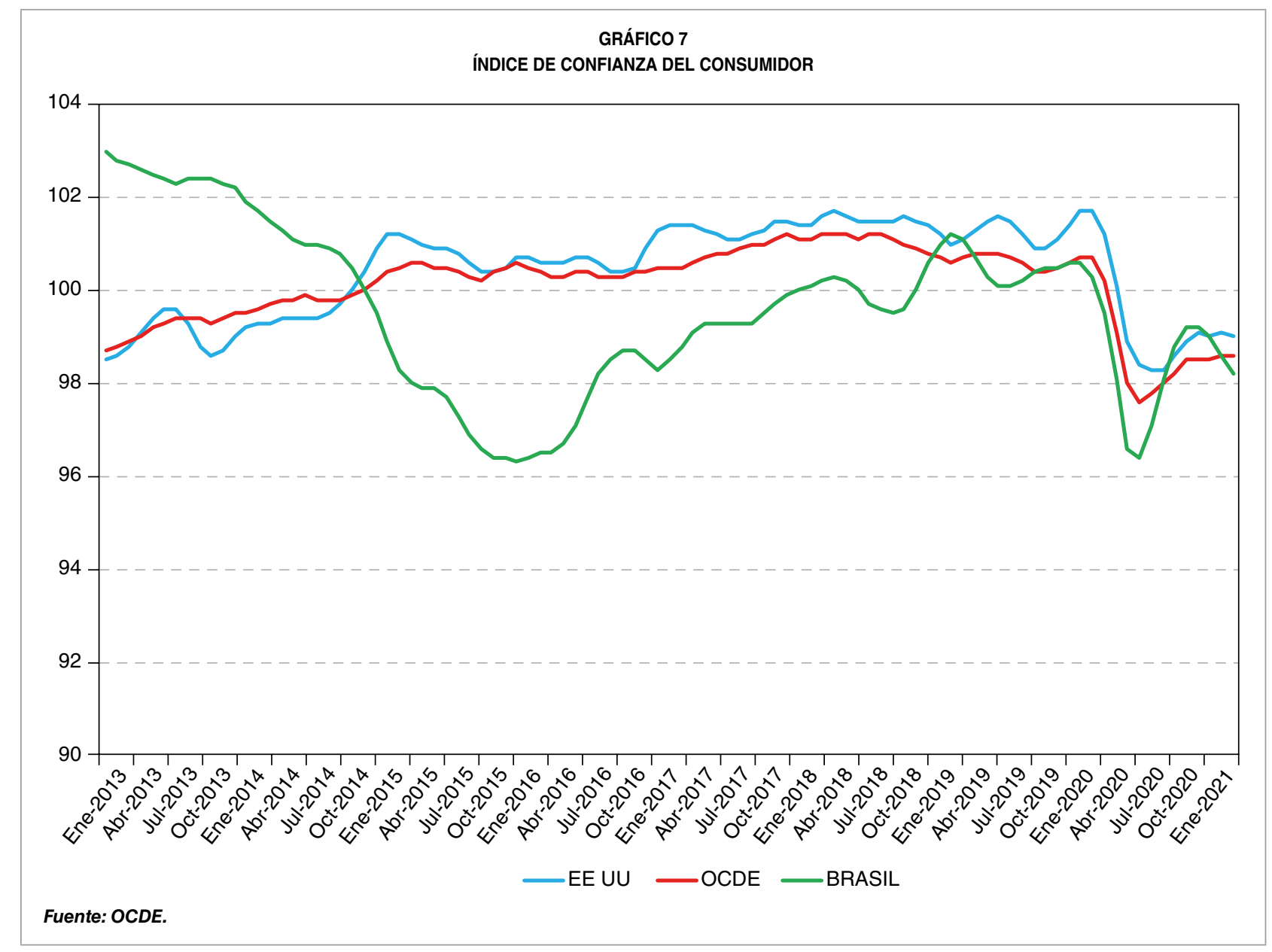

El impacto de las medidas de aislamiento social y descenso de la actividad tuvieron su reflejo en diversos indicadores además de sobre el PIB:

- El índice de confianza empresarial (ICE) de la Fundação Getulio Vargas (FGV), publicado en abril de 2020, cayó 33,7 puntos en el mes de abril, situándose en 55,8 puntos, el menor nivel desde el comienzo de la serie histórica iniciada en 2001.

- El índice de confianza del comercio (ICOM) de la FGV, publicado en abril, mostró un descenso de 26,9 puntos para el mes de abril, hasta los 61,2, siendo el valor más bajo de la serie histórica.
- El índice de confianza de servicios (ICS) de la FGV, publicado en abril, disminuyó 31,7 puntos en el mes de abril, pasando a situarse en el nivel 51,1; el más bajo de la serie histórica, iniciada en junio de 2008.

- El indicador índice de gestores de compras de servicios (PMI), de servicios de IHS Markit de Brasil, publicado en mayo, mostraba que en abril el indicador se situó en el nivel 27,4 frente al resultado de 34,5 en marzo, señalando la mayor caída en la actividad en el sector servicios desde que se inició la encuesta, en 2007. Además, la caída supuso el hundimiento del índice por debajo de la marca de 50 puntos, $D$ 
umbral que separa la previsión de crecimiento de la de contracción.

- Por su parte, el indicador PMI del sector de manufacturas (sector industrial), publicado en mayo, mostraba un descenso para el mes de abril hasta el nivel 36 desde el dato de marzo $(48,8)$, mostrando estos datos la sensible y repentina contracción del sector industrial brasileño después del brote de la COVID-19. Los volúmenes de producción y los nuevos pedidos disminuyeron significativamente en el periodo, con una retracción aún más grave que la registrada en la crisis financiera mundial de 2007-2008, siendo el peor dato desde el comienzo de la serie, catorce años atrás.

- Así, los datos del índice consolidado de producción de IHS Markit mostraron una caída hasta los 26,5 puntos en comparación con el nivel 37,6 de marzo. El registro de abril fue el más bajo en la historia del indicador, haciendo eco de las caídas récord con respecto a la producción tanto en el sector industrial como en el de servicios.

- El indicador de incertidumbre de la economía de la FGV (IIE-Br), publicado en abril, mostró un ascenso de 43,4 puntos para el mes de abril, hasta situarse en 210,5 puntos. Este avance de la incertidumbre, consecuencia de la pandemia de coronavirus (COVID-19), llevó al indicador a su nivel más alto de la serie histórica.

- En el mercado de trabajo, la Encuesta Nacional por Muestra de Domicilios Continua Trimestral (PNAD) del IGBE, para el trimestre móvil marzo-abril-mayo, es decir, contemplando los peores meses de la crisis económica derivada del freno en la actividad, mostró que la tasa de desocupación aumentó 1,2 pp (puntos porcentuales) en relación con los tres meses anteriores, elevándose hasta el $12,9 \%$. La población ocupada (85,9 millones de personas) disminuyó un $8,3 \%$ en relación con el periodo anterior, y el número de personas desalenta$\operatorname{das}^{3}$ (5,4 millones) aumentó un 15,3\% en comparación con el trimestre móvil inmediatamente anterior. Por su parte, el número de trabajadores por cuenta propia (22,4 millones de personas) se redujo un $8,4 \%$ en comparación con el trimestre precedente.

- Las actuaciones/medidas llevadas a cabo por el Gobierno federal situaban, en mayo, el déficit público nominal en 638.600 millones de reales, un $8,8 \%$ del PIB, cuando al cierre de 2019 se había situado en el 5,8\% del PIB.

- En el mes de abril, los datos del Instituto Brasilero de Geografia e Estadistica (IBGE) publicados para el índice nacional de precios al consumidor amplio (IPCA) mostraban una caída del indicador del 0,3\% intermensual, frente a la práctica estabilización de marzo (0,07\%). En el acumulado de los últimos doce meses, la tasa de inflación se situaba en el 2,4\%, por debajo del objetivo de inflación del Banco Central de Brasil para 2020 (4\%), e incluso por debajo del límite inferior de tolerancia establecido, de $+/-1,5$ puntos porcentuales. En mayo, esta trayectoria descendente se mantuvo, de manera que el IPCA aceleró su descenso intermensual en 7 centésimas $(-0,8 \%$ intermensual), y en el acumulado de los $\triangleright$

\footnotetext{
3 Parados de larga duración que desisten de buscar empleo.
} 
últimos doce meses la tasa de inflación se situaba en el 1,9\%, de nuevo por debajo del objetivo de inflación del Banco Central y del límite inferior de tolerancia.

Prácticamente coincidiendo con el cambio de actitud y beligerancia del presidente Bolsonaro, y del inicio del reflejo de los efectos derivados de las medidas, los resultados de los indicadores coyunturales empezaron a mejorar levemente dentro de la gravedad de la situación:

- El índice de confianza del consumidor (ICC) de la FGV aumentó 3,9 puntos en mayo, hasta el nivel 62,1; suponiendo este resultado una pequeña recuperación tras una caída acumulada de 29,6 puntos en los meses de marzo y abril de 2020.

- El índice de confianza de la industria (ICI), publicado en mayo por la FGVIBRE, avanzó 3,2 puntos, situándose en el nivel 61,4. El avance registrado en mayo suponía una recuperación respecto a la pérdida acumulada entre febrero y abril de 2020 ( $-43,2$ puntos).

- El índice de confianza del comercio (ICOM) de la FGV, publicado en mayo, mostró un crecimiento de 6,2 puntos para el mes de mayo, hasta el nivel 67,4, tras una caída acumulada en el índice de 38,6 puntos en los meses de marzo y abril de 2020.

- El índice de confianza de servicios (ICS) de la FGV, publicado en mayo, aumentó 9,4 puntos, pasando a situarse en el nivel 60,5, tras las pérdidas acumuladas de los últimos dos meses (-43,3 puntos).

- El indicador de incertidumbre de la economía de la FGV (IIE-Br), publicado en mayo, mostró una caída de 20,2 puntos para ese mes, hasta situarse en el nivel 190,3; cambiando la tendencia tras un bimestre (marzo-abril de 2020) en el que el indicador acumuló una subida de 95,4 puntos.

- Según el PMI de servicios de IHS Markit de Brasil, publicado en junio, el indicador se situó en el nivel 27,6 en mayo, frente al resultado de 27,4 en abril, indicando así que la pandemia de coronavirus (COVID-19) continúa teniendo un impacto sustancial en el desempeño de la economía brasileña de servicios.

- Por su parte, el PMI del sector de manufacturas (sector industrial), publicado en junio, indicaba un incremento en mayo hasta el nivel 38,3. A pesar de la mejora respecto a abril, el PMI del sector de manufacturas continuaba mostrando un deterioro sin precedentes en la salud del sector y se mantuvo por debajo de los 50 puntos por tercer mes consecutivo.

- Así, los datos del índice consolidado de producción, publicado en junio, registraron un ligero cambio de tendencia al alza en mayo, subiendo al nivel 28,1, en comparación con el nivel 26,5 de abril. A pesar de presentar el primer resultado positivo de los últimos meses, se mantuvo muy por debajo de la marca de los 50 puntos, revelando una caída sustancial de la inversión privada, así como una fuerte contracción, tanto del sector servicios como del manufacturero.

Así las cosas, es a partir de agosto cuando las empresas empiezan a reportar mejoras en su facturación y en el clima de negocio, y en septiembre algunos indicadores empiezan a recuperar los niveles previos al estallido de la pandemia:

- El índice de confianza de la industria (ICI), publicado en septiembre por la $\triangleright$ 
FGV-IBRE, avanzó 8 puntos, situándose en el nivel 106,7, el mayor desde enero de 2013 y ya superando el registrado antes de la pandemia (101,4 puntos en febrero).

- El índice de confianza del comercio (ICOM) de la FGV, publicado en septiembre, mostró un crecimiento de 3 puntos en ese mismo mes, situándose en el nivel 99,6, lo que representa el quinto mes consecutivo con resultados positivos y aproximándose al nivel registrado antes de la pandemia $(99,8$ puntos en febrero).

- Por su parte, el PMI del sector de manufacturas (sector industrial), publicado en septiembre, mostró un incremento en agosto, alcanzando el nivel 64,7, el resultado más alto de la serie histórica y muy por encima del nivel prepandemia $(50,4$ puntos).

- Así, los datos del índice consolidado de producción, publicado en septiembre, reflejaban la consolidación del cambio de tendencia al alza, con una nueva subida de 6,6 puntos, hasta el nivel 53,9, ya por encima de los niveles anteriores a la crisis $(50,9$ en febrero).

- El indicador de incertidumbre de la economía de la FGV (IIE-Br), publicado en septiembre, reflejó una caída de 14,5 puntos para el mes, hasta situarse en el nivel 145,8 puntos, lejos ya del máximo histórico de 210 puntos registrado en abril.

La finalización del año y, con él, la vigencia del auxilio de emergencia sin un plan claro para los millones de personas que han dejado de recibir esa ayuda han recuperado cierta sensibilidad en el sistema, llevando a pensar en un inicio de año menos positivo de lo esperado, incertidumbre alimentada también por la falta de estrategia clara en la gestión de las vacunas y la duración de la pandemia:

- El índice de confianza del consumidor (ICC) de la FGV cayó 3,2 puntos en diciembre, hasta el nivel 78,5 , registrando el tercer descenso consecutivo, lo que podría estar reflejando la incertidumbre en torno a la finalización de la ayuda de emergencia a final de diciembre y las elevadas cifras de desempleo.

- El índice de confianza de la industria (ICI), publicado en diciembre por la FGVIBRE, avanzó 1,8 puntos, situándose en el nivel 114,9, el mayor desde mayo de 2010 (116,1 puntos).

- El índice de confianza del comercio (ICOM) de la FGV, publicado en diciembre, mostró una caída de 1,8 puntos en ese mismo mes, registrando un descenso por tercer mes consecutivo, lo que sitúa al índice en el nivel 91,7.

- El índice de confianza de servicios (ICS) de la FGV, publicado en diciembre, aumentó 0,8 puntos en el mes, pasando a situarse en el nivel 86,2, afianzando el ritmo de crecimiento gradual desde el mínimo histórico alcanzado en abril.

- Según el PMI de servicios de IHS Markit de Brasil, publicado en diciembre, el indicador se situó en el nivel 50,9 en noviembre (52,3 en octubre).

- Por su parte, el PMI del sector de manufacturas (sector industrial), publicado en diciembre, mostró un descenso en noviembre, alcanzando el nivel 64 (66,7 en octubre, el nivel más alto de la serie histórica).

- Así, el índice consolidado de producción de Markit, publicado en diciembre, interrumpió tres meses de aumento $\triangleright$ 
consecutivo de la producción del sector privado en todo Brasil. El índice registró en noviembre un nivel de 53,8 (55,9 en octubre), lo que muestra una ralentización del ritmo esperado de avance en el sector privado brasileño, si bien se mantiene por encima del nivel 50.

- El indicador de incertidumbre de la economía de la FGV (IIE-Br), publicado en diciembre, muestra una caída de 5 puntos para el mes, hasta situarse en el nivel 140,8 puntos, aún por encima del nivel prepandemia registrado en febrero (114,8 puntos).

- En diciembre, la Encuesta Nacional por Muestra de Domicilios Continua Trimestral (PNAD) del IGBE, para el trimestre móvil agosto-octubre de 2020, mostró que la tasa de paro aumentó 0,5 pp en relación con los tres meses anteriores, elevándose hasta el 14,3\%. En relación con el mismo trimestre móvil del año anterior, el aumento fue de 2,7 pp (11,6\% un año antes). El número de personas desalentadas (5,8 millones) permaneció estable en relación con el trimestre inmediatamente anterior, si bien aumentó un $25 \%$ frente al mismo trimestre de 2019 (4,7 millones de personas).

El cierre del año 2020, para diversos indicadores, es complicado, sobre todo en lo que se refiere a las cuentas públicas, que han finalizado el año con un déficit primario del 9,5\% del PIB y un déficit nominal del $13,7 \%$ del PIB, dificultando el margen de actuación de la política fiscal. La Ley de Directrices Presupuestarias (LDO) de 2021, aprobada en diciembre de 2020, estima que el déficit primario para el ejercicio 2021 alcanzará los 247.100 millones de reales, proyectando escenarios negativos tanto en 2022 como en 2023 (-178.930 y -150.130 millones de reales, respectivamente). Por otra parte, se prevé que la deuda bruta del Gobierno alcance el $84,3 \%$ del PIB en 2021, el $85,5 \%$ del PIB en 2022 y el $86,4 \%$ del PIB en 2023. Así pues, una vez que finalice la situación de emergencia derivada de la pandemia de coronavirus, Brasil tendrá que llevar a cabo las reformas estructurales necesarias que permitan equilibrar las cuentas públicas y reducir la carga de la deuda, ya que las previsiones indican que, aunque se cumpliera el techo de gasto, existiría un déficit primario que se mantendría hasta 2027, año en el que se podría cambiar la tendencia deficitaria que comenzó en 2014 y registrar el primer superávit tras trece años consecutivos de déficit.

\section{Medidas de apoyo a la lucha contra la pandemia}

Muchas son las medidas articuladas por el equipo económico del Gobierno Bolsonaro desde el inicio de la pandemia, con un enorme impacto en los objetivos de estabilización fiscal del ministro Paulo Guedes.

Tal y como presentaba recientemente el secretario especial de Fazenda (en diciembre de 2020), se ha registrado al cierre del ejercicio 2020 un incremento inesperado del gasto de 590.000 millones de reales y unos menores ingresos (por las medidas tomadas y la menor actividad) por valor de 26.200 millones de reales. Así, el déficit primario se sitúa, por el momento, en 620.500 millones de reales, lo que supone un déficit primario del $9,6 \%$ del PIB, que sitúa el déficit nominal en el $13,7 \%$ del PIB.

A modo de resumen, se presenta la Tabla 1 con las principales medidas tomadas y su impacto monetario. 


\section{IMPACTO DE LA PANDEMIA DE LA COVID-19 SOBRE LA ECONOMÍA BRASILEÑA}

\section{TABLA 1 \\ RESUMEN DE LAS MEDIDAS COVID}

Impacto en el Resultado Primario de 2020 (millones de reales)

Ingresos (I)

Reducción temporal (a cero) de los impuestos de importación de los bienes de uso médico y hospitalario. Resoluciones CAMEX 17, 22, 28, 31, 32, 33, 44, 51, 67 e 75

Reducción temporal (a cero) de las tasas de importación por correo postal o aéreo. Régimen tributario simplificado. Ordenanza ME 158, 194

Exención temporal de IPI para bienes necesarios contra la COVID-19. Decretos 10.285, 10.302

Reducción temporal de IOF crédito. Decretos 10.305, 10.414, 10.504

Exención temporal de PIS/COFINS (sulfato de zinc para medicamentos). Decreto 10.318

Suspensión del pago de deudas de la Seguridad Social. Ley Complementar 173; Ordenanza RFB 1.072

Gastos (II)

\section{En ejecución presupuestaria}

Ampliación de recursos para salud y educación, para adquisición de insumos médicos y hospitalarios. MPV 924

Reubicaciones COVID-19

Transferencias al Fondo Nacional de Salud. Compras de epis y respiradores. MPV 947

Crédito del Ministerio de Salud para ampliar la adquisición de test de COVID-19. MPV 967

Contratación temporal de personal de salud (5.000 profesionales) (MS). MPV 970

Transferencia complementaria al Fondo Nacional de Salud. MPV 976

Ayuda financiera a santas casas y hospitales sin fines lucrativos (complementar SUS). MPV 967; Lei 13.995

Ayuda a estados y municipios, transferencias salud, emendas parlamentares. MPV 941, Ley 14.032

Ayuda a estados y municipios, transferencias al Fondo Nacional de Salud. MPV 940

Transferencias adicionales a estados y municipios y al Distrito Federal para financiar las acciones en el ámbito sanitario. MPV 969

Ayuda a estados y municipios. Compensación FPE e FPM. MPV 938, 939; Ley 14.042

Ayuda financiera de emergencia federativa (4 meses). MPV 978; Ley Complementar 173

Protección social en el ámbito del Sistema Único de Asistencia Social (SUAS). MPV 953

Ampliación del Programa Bolsa Familia. MPV 929

Ayuda financiera de emergencia (600 reales mensuales por 5 meses). MPV 937, 956, 970, 988; Ley 13.982; MP 999, 1000

Ciudadanía. Seguridad alimentaria y nutricional. MPV 957

Transferencia a la Cuenta de Desarrollo Energético (Tarifa Social). MPV 949

Beneficio de mantenimiento de ingresos y empleo de emergencia. MPV 935, 936; Ley 14.020

Programa de Apoyo al Empleo de Emergencia (Nómina-PESE Funding União). MPV 943, 944

Pronampe. MPV 972; Ley 13.999 Programa Nacional de Apoyo a la Micro y Pequeña Empresa

FGI. BNDES. MPV 975, 977. Programa de acceso al crédito de emergencia (Fondo de garantía de inversiones)

Plan nacional de inmunización contra la COVID. MPV 1.015

Programa de Emergencia de Acceso al Crédito (PEAC). Datáfonos. Ley 14.042

Apoyo de emergencia del sector cultural. MPV 990; Ley 14.017

Acceso global a las vacunas COVID-19. Covax Facillity. MPV 1.004

Créditos extraordinarios ministerios. MPV 921, 929, 940, 941, 942, 962, 965, 985, 989, 991,994, 1001, 1007, 1008; Ley 14.033

\section{Sin dotación presupuestaria}

(Fies) Ley 13.998. Suspensión de las cuentas de préstamos del fondo de financiación estudiantil

Expansión FGI. Ley 14.042

Fuente: Ministério da Economia, Brasil. 
Estas medidas habrían conseguido amortiguar en cierta forma el impacto de la COVID-19 sobre la economía brasileña, tal y como recoge el indicador adelantado de la OCDE (composite leading indicator).

Dentro del conjunto de medidas, especial referencia merecen las que podrían incluirse en el grupo de medidas de asistencia social, las del grupo de medidas laborales, las del grupo de medidas de financiación, las medidas fiscales o las comerciales, entre otras.

\subsection{Medidas de asistencia social}

En este apartado destacan:

- Ayudas de emergencia para población vulnerable. En el mes de abril entró en vigor la Ley 13.982, que puso en marcha el denominado y conocido como «auxilio emergencial» (ayuda de emergencia), que ha sido la principal medida de emergencia entre los meses de abril y agosto para el sustento de cerca de 65 millones de personas en situación de pobreza, a través del pago de 600 reales de ayuda de emergencia mensual para autónomos, empleados informales, desempleados que ya hubiesen agotado el seguro de desempleo o personas ajenas a la fuerza de trabajo, o de bajos ingresos. Esta medida, prevista primero para tres meses, fue prorrogada en su cuantía inicial hasta agosto y después hasta diciembre por la mitad, 300 reales, hasta su extinción el 31 de diciembre de 2020.

- Aumento de la dotación en 3.100 millones de reales para distribuir a los beneficiarios del programa de Bolsa
Familia $^{4}$, destinado a aquellas personas consideradas en situación de extrema pobreza (ingresos mensuales menores de 89 reales), o una retribución parcial para aquellas personas con ingresos mensuales entre 89 y 178 reales. Actualmente, cerca de 13 millones de brasileños se benefician de este programa, que podrá cubrir a cerca de un millón de personas más con estos nuevos recursos.

- Garantía de suministro eléctrico. La Agencia Nacional de Energía Eléctrica (Aneel) anunció que suspendería de marzo a julio los cortes en el suministro de energía eléctrica a los consumidores residenciales urbanos y rurales y también a las actividades esenciales que no hubiesen pagado sus facturas.

- Aplazamiento de pagos y renegociación de hipotecas. La mayoría de los principales bancos comerciales del país ofrecieron a sus clientes la posibilidad aplazar el pago de las cuotas de hipotecas para viviendas y renegociar sus hipotecas.

\subsection{Medidas laborales}

Entre estas medidas destacan:

- Preservación del empleo. Como acciones para la preservación del empleo destacan, entre otras, las siguientes: $\triangleright$

4 Bolsa Família es un programa de la Secretaría de Renta de la Ciudadanía Nacional (Senarc), que contribuye a la lucha contra la pobreza y la desigualdad en Brasil. Fue creado en octubre de 2003 y tiene tres ejes principales: (i) complemento de ingresos; (ii) acceso a derechos; y (iii) articulación con otras acciones para estimular el desarrollo de las familias. La gestión de Bolsa Família es descentralizada, es decir, tanto la Unión como los estados, el Distrito Federal y los municipios tienen atribuciones en su ejecución. A escala federal, el Ministerio de Ciudadanía es responsable del Programa, y Caixa Econômica Federal es el agente que ejecuta los pagos. 
- MP N. 936/2020: Programa de mantenimiento de emergencia de empleo e ingresos y medidas laborales complementarias.

- MP N. 944/2020: Programa de apoyo laboral de emergencia (para empresas con ingresos brutos anuales entre 360.000 y 10 millones de reales).

- Las Órdenes Ministeriales (n.- 139 y 150) que contemplan las prórrogas establecidas para el pago de tributos federales como el PIS/PASEP o COFINS y la Ley N.1․ 13.982, conocida como la «Ley de Coronavoucher", con los detalles sobre el programa de ayudas para personas de renta baja.

\subsection{Medidas de financiación}

Entre estas medidas destacan:

- El Gobierno federal y el Banco Nacional de Desarrollo Económico y Social (BNDES) anunciaron medidas de emergencia para ayudar a mitigar los efectos de la pandemia en Brasil. El monto total a ser desembolsado será de 55.000 millones de reales, de los que se destinarán, entre otros, 19.000 millones de la suspensión temporal de pagos de cuotas de financiación directa a empresas, tanto de capital como de intereses, 11.000 millones en reestructuraciones de la financiación de empresas (standstill financiero) y 5.000 mil millones serán destinados a la expansión del crédito para micro, pequeñas y medianas empresas a través de bancos asociados.

- Desde marzo, el BNDES ha lanzado líneas de financiación de emergencia dirigidas a diversos sectores del mercado, entre ellas destacan:
- Las líneas de crédito para aportar capital de giro a pymes con facturación anual de hasta 300 millones de reales y un límite de financiación de 70 millones de reales, o poner a su disposición los fondos destinados al Programa de Emergencia de Acceso a Crédito (PEAC) aprobado como Ley 14.042 de 2020, o la obtención de microcréditos a través de los datáfonos.

- Créditos a las empresas de las principales cadenas productivas y del comercio mayorista y minorista. El BNDES ha estructurado una línea de financiación para apoyar la cadena de suministro de los segmentos más afectados por la nueva pandemia de coronavirus, denominada por el banco como «Crédito Ancla» (Crédito Âncora, en portugués).

- Líneas de crédito destinadas a sectores específicos, como las empresas que actúan en el área de salud o las empresas de producción de azúcar y etanol.

- Líneas de crédito para la cobertura de nóminas. De acuerdo con la Ley $n .$. 14.043, el BNDES podrá financiar hasta dos salarios mínimos, o 2.090 reales por trabajador durante un plazo acordado con la empresa, si bien, como contrapartida, la empresa no podrá despedir de forma improcedente a ninguno de sus empleados hasta dos meses después de la recepción del último desembolso del crédito.

- El Gobierno brasileño creó el Programa Nacional de Apoyo a Microempresas y Empresas de Pequeño Porte (Pronampe) por valor de 15.900 millones de reales, que, de acuerdo con la Ley 13.999/2020, otorgará líneas de $\triangleright$ 
crédito con un importe máximo del $30 \%$ de los ingresos brutos anuales registrados por la empresa, excepto para aquellas que se encuentren en su primer año de operación, donde el límite podrá alcanzar el $50 \%$ de su capital social o hasta el $30 \%$ del promedio de sus ingresos mensuales, lo que sea más ventajoso.

- El Consejo Monetario Nacional (CMN) autorizó la creación de líneas de crédito especiales con recursos de los Fondos de Financiamiento Constitucional del Norte (FNO), el Noreste (FNE) y el Medio Oeste (FCO) para el sector productivo. La tasa de interés sobre el financiamiento será de $2,5 \%$ por año. Estas líneas de crédito se destinarán a la industria, el comercio y los servicios de los municipios afectados por la emergencia de salud pública relacionada con la COVID-19. La nueva línea fue introducida por la Resolución 4.798, publicada por el Ministerio de Economía.

- El Consejo Monetario Nacional (CMN) reguló la concesión de préstamos mediante el nuevo el Programa de Apoyo al Empleo de Emergencia, PESE, creado por la Medida Provisional 944/2020. Para preservar los empleos, PESE abrió una línea de crédito de emergencia de 40.000 millones de reales para financiar la nómina de las pequeñas y medianas empresas. EI PESE estará dirigido a empresas y cooperativas (a excepción de las cooperativas de crédito) con ingresos brutos anuales entre 360.000 reales y 10.000 .000 reales. Se estima que el programa beneficia a cerca de 12,2 millones de empleados en 1,4 millones de pymes.

- Financiación de deudas con el Gobierno federal. El Gobierno creó la Medida Provisória 958 (medida provisional) que permite la concesión de préstamos con recursos públicos a empresas que tengan deudas con el Gobierno federal, ya que pasa a prescindir de una serie de requisitos previstos en la legislación actual, facilitando la financiación pública para las empresas con deudas fiscales y FGTS (Fondo de Garantía de los Trabajadores), por ejemplo. Esta medida permanecerá vigente hasta el 30 de septiembre de 2020.

- Préstamos destinados a grandes empresas. Los principales bancos brasileños han formado un consorcio para ofrecer, con el apoyo del Gobierno federal, un rescate financiero para las grandes empresas (con facturación superior a 300 millones de reales anuales) que formen parte de los sectores más afectados por la nueva pandemia de coronavirus. Su idea es crear una línea de crédito con condiciones específicas para las empresas de los sectores económicos que prácticamente han dejado de funcionar debido a la COVID-19, como las aerolíneas y las fábricas de automóviles.

- El Servicio Brasileño de Apoyo a las Micro y Pequeñas Empresas (Sebrae) habilitó una línea de crédito para distribuir 12.000 millones de reales en microcréditos de hasta 20.000 reales para incrementar el capital de pequeñas empresas, junto con la Caixa Econômica Federal, el BNDES y el Banco de Brasil.

\subsection{Medidas fiscales}

Entre estas medidas destacan:

- Atraso de tres meses en el pago de tributos (entre marzo y junio) por parte $\triangleright$ 
de empresas al conjunto de nueve instituciones de interés en categorías profesionales, establecido por la Constitución brasileña, denominadas como «Sistema S». Entre ellas destacan el Servicio Social del Comercio (SESC), el Servicio Social de la Industria (SESI) o el Servicio de Apoyo a las Micro y Pequeñas Empresas (SEBRAE). (Ley 14.025/2020).

- Ampliación del plazo límite para la entrega de la declaración de la renta. Los contribuyentes pudieron entregar su declaración hasta final de junio, en lugar de en abril, cuando suele cerrarse el plazo. La fecha límite pasó del 30 de abril al 30 de junio.

- Extensión del plazo para presentar las cuentas anuales de empresas. La Receita Federal ha publicado la Instrucción Normativa RFB N. 1.950 , que extiende el plazo para el envío de la contabilidad digital (ECD) del año 2019 al Sistema Público de Contabilidad Digital (Sped), originalmente previsto para el 30 de mayo, pasándolo al 31 de julio. Tras haber recibido numerosos pedidos de aplazamiento por parte de empresas de contabilidad y servicios de auditoría, están teniendo dificultades para llevar a cabo estas actividades debido a las restricciones derivadas de la pandemia.

- Aplazamiento de cuotas pagadas por empresas a la Receita Federal. El Ministerio de Economía publicó la Orden $n^{\circ}$ 201/2020 que aplaza los pagos previstos para los meses de mayo, junio y julio de las cuotas administradas por la Receita Federal y por la Fiscalía General de la República, cuyo pago se producirá en los meses de agosto, octubre y diciembre, respectivamente. Del mismo modo, se suspenderán también las retenciones del Fondo de Participación de los Estados y Municipios relacionadas destinadas a estos órganos federales. El ministerio estima que el total de recaudación aplazada ascienda a 9.580 millones de reales.

\subsection{Medidas comerciales}

Entre estas medidas destacan:

- Eliminación temporal del impuesto de importación (II) incidente sobre productos destinados al combate de la pandemia. El Comité Ejecutivo de Gestión de la Cámara de Comercio Exterior (CAMEX) publicó en marzo la Resolución $\mathrm{n}$.을 $17 / 2020$, en la que se presentaba un primer listado de bienes destinados al combate de la pandemia exentos temporalmente del impuesto de importación, que después ha sido actualizado a partir de una serie de nuevas resoluciones. El listado actualizado de productos exentos puede consultarse en el Anexo de la Resolución CAMEX n.ำ17/2020.

- Eliminación temporal del impuesto sobre productos industrializados (IPI). En mayo se publicó el Decreto Presidencial

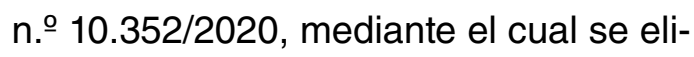
minaba hasta octubre la incidencia de este impuesto sobre varios productos destinados al combate de la pandemia; posteriormente se han publicado nuevos decretos que han añadido nuevos productos a la lista inicial.

- Aumentos de plazo para operaciones en la modalidad Drawback. Se establece la

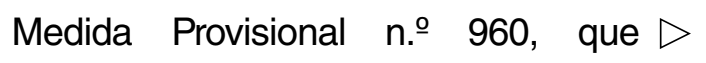


autoriza a la Secretaría de Comercio Exterior (Secex) del Ministerio de Economía a extender, por un año, y de manera excepcional, el plazo de validez de procesos de comercio internacional en régimen de Drawback, que tengan plazo de extinción en 2020. El Gobierno estima que se encuentran suscritos a este régimen operaciones de comercio internacional con valor total cercano a 23.000 millones de reales.

- La Receita Federal simplificó el despacho de aduanas de productos para uso médico y hospitalario, que podrá ser liberado de forma inmediata una vez determine el despachante que se trata de bienes de necesidad para el combate de la epidemia. En RFB 1.927 y la Instrucción

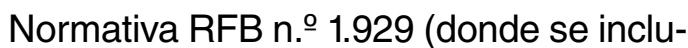
yen también los bienes para el combate a la pandemia sujetos a extarifarios).

- Eliminación de la exigencia de licencias de importación y despacho de importación prioritario para algunos productos destinados al combate de la epidemia, a modo de agilizar su llegada al mercado interno. SECEX N ․o 18/2020 y la Orden (Portaria) N. 25/2020. Además, la Receita Federal publicó la Instrucción
Normativa $N^{\circ} 1.936 / 2020$, mediante la cual se extiende el plazo para presentar el Certificado de origen a 60 días después del registro de la Declaración de Importación.

- Reducción de plazos para la emisión de autorizaciones de importación. El Gobier-

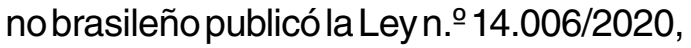
que modifica la Ley $\mathrm{N} .^{\circ} 13.979$, de 6 de febrero de 2020, pasando a establecer un período máximo de 72 horas para que la Agencia Nacional de Vigilancia Sanitaria (Anvisa) autorice la importación y distribución de cualquier material, medicamento, equipo o insumo del área de salud que haya sido ya registrado por una autoridad de salud extranjera reconocida, y que haya sido ya autorizado para la distribución comercial en sus respectivos países.

\section{Situación actual de la pandemia en Brasil}

\subsection{Situación sanitaria}

La Tabla 2 recoge una muestra de la situación actual, en términos de casos acumulados por semana epidemiológica y decesos, en $\triangleright$

TABLA 2

DATOS ACUMULADOS DE COVID-19

\begin{tabular}{|c|c|c|c|c|c|}
\hline \multirow{2}{*}{ Estado } & \multirow{2}{*}{$\begin{array}{l}\text { Casos } \\
\text { acumulados }\end{array}$} & \multirow{2}{*}{$\begin{array}{l}\text { Defunciones } \\
\text { acumuladas }\end{array}$} & \multicolumn{3}{|c|}{ Indicadores } \\
\hline & & & Tasa de letalidad & Tasa de mortalidad* & Tasa de incidencia* \\
\hline São Paulo & 1.938 .712 & 56.960 & $2,9 \%$ & 124,0 & 4.222 \\
\hline Santa Catarina & 622.727 & 6.804 & $1,1 \%$ & 95,0 & 8.692 \\
\hline Minas Gerais & 816.901 & 17.109 & $2,1 \%$ & 80,8 & 3.859 \\
\hline Distrito Federal & 286.720 & 4.718 & $1,6 \%$ & 156,5 & 9.509 \\
\hline Bahia & 639.227 & 10.928 & $1,7 \%$ & 73,5 & 4.298 \\
\hline Amazonia & 299.495 & 10.181 & $3,4 \%$ & 245,6 & 7.226 \\
\hline Brasil & 9.978 .747 & 242.090 & $2,4 \%$ & 115,2 & 4.749 \\
\hline \multicolumn{6}{|c|}{$\begin{array}{l}\text { Fecha de consulta: } 18 / 02 / 21 \text { referente al periodo entre las } 16 \mathrm{~h} \text { del día anterior a las } 16 \mathrm{~h} \text { de la fecha de consulta. } \\
{ }^{*} \text { Datos por cada } 100.000 \text { habitantes. }\end{array}$} \\
\hline
\end{tabular}


la misma base de comparación desde el inicio de la pandemia hasta el 17 de febrero de 2021 para algunos de los estados más relevantes, ya sea por su importancia económica (caso de São Paulo, Santa Catarina o Minas Gerais) o por el impacto y virulencia de la crisis (casos del Distrito Federal, Bahia o Amazonas).

\subsection{Situación política}

Como se ha comentado anteriormente, la actualidad del país muestra cierta tensión política, derivada de la conocida como «guerra de las vacunas» en referencia a las diferentes posiciones entre, principalmente, el presidente Bolsonaro y el gobernador de São Paulo, João Doria. En este contexto, hay tensión también sobre la gestión en la distribución de las vacunas e insumos realizada por el ministro de Sanidad, llegando a barajarse incluso su cese en algunos momentos, al igual que sobre la gestión diplomática infructuosa desarrollada por el canciller Araujo, sobre el que también existen dudas sobre su continuidad.

Estos posibles cambios en el Gabinete Bolsonaro estarían también asociados a la negociación política derivada de las elecciones a la Cámara y al Senado para conseguir el nombramiento de sus candidatos, con vista a poder continuar el avance de las reformas previstas por Guedes.

\subsection{Situación económica}

En el mes de enero, el Banco Central de Brasil (BCB) publicó los datos del índice de actividad económica (IBC-Br) hasta noviembre de 2020, indicador creado para anticipar el resultado del producto interior bruto (PIB). Con datos desestacionalizados, la actividad del país registraría un crecimiento intertrimestral del 4,4\%. El dato mensual sería de un decrecimiento del 0,6\%, y con respecto al mismo mes de 2019 habría un descenso del 0,8\%. En el acumulado hasta noviembre de 2020 , el indicador avanza una variación negativa del 4,6\%.

En cuanto a los indicadores de confianza, el índice de confianza del consumidor (ICC) de la Fundación Getulio Vargas (FGV) cayó 2,7 puntos en enero, hasta el nivel 75,8 , en lo que sería el cuarto descenso consecutivo y el menor valor desde junio de 2020 (71,1 pp). Sin el apoyo de las prestaciones de emergencia, las familias seguirían posponiendo el consumo y dependen de la recuperación del mercado laboral, que está siendo lenta en el escenario actual.

El índice de confianza de la industria (ICI), publicado en enero por la FGV-IBRE, retrocedió 3,6 puntos, situándose en el nivel 111,3. Es el primer resultado negativo del sector después de ocho meses de altas consecutivas.

El índice de confianza del comercio (ICOM) de la FGV, publicado en enero, mostró una caída de 0,9 puntos en el primer mes del año, hasta el nivel 90,8, cuarto descenso consecutivo.

El índice de confianza de servicios (ICS) de la FGV, publicado en enero, retrocedió 0,7 puntos en el mes, pasando a situarse en el nivel 85,5 .

Según el PMI de servicios de IHS Markit de Brasil, publicado en enero, el indicador se situó en el nivel 51,1 en diciembre $(50,9$ en noviembre), mostrando una tasa de expansión leve y un aceleramiento de la producción. El aumento se asocia a la mejoría de las perspectivas respecto a la COVID-19 debido a las noticias positivas sobre la vacuna.

Por su parte, el PMI del sector de manufacturas (sector industrial), publicado en enero, mostró el segundo descenso consecutivo $D$ 
desde noviembre (66,7 puntos), alcanzando el nivel 61,5 después de una caída de 2,5 puntos respecto a diciembre (64 puntos en noviembre).

Así, el índice consolidado de producción de Markit, publicado en enero para diciembre, interrumpió tres meses de aumento continuo de la producción del sector privado en todo Brasil. El índice registró un nivel de 53,5 (53,8 en noviembre), indicando una cierta ralentización del ritmo de crecimiento de la producción por segundo mes consecutivo.

Finalmente, el indicador de incertidumbre de la economía de la FGV (IIE-Br), publicado en enero, muestra una caída de 3,5 puntos para el mes de diciembre, hasta situarse en el nivel 142,3 puntos. Con este resultado, el indicador se encuentra 27,5 puntos por encima del nivel prepandemia registrado en febrero $(114,8$ puntos), apuntando aún a elevados niveles de incertidumbre.

Asimismo, según los datos del IBGE publicados en enero, la evolución del índice nacional de precios al consumidor amplio (IPCA) durante el año 2020 se habría situado en el 4,5\%, dos décimas superior al resultado de 2019 $(4,3 \%)$, quedando por encima del objetivo de inflación del Banco Central de Brasil para 2020 (4\%), aunque dentro del límite superior de tolerancia establecido, de +/- 1,5 puntos porcentuales. Por su parte, sin embargo, el índice general de precios-mercado (IGP-M) ${ }^{5}$ de la FGV-IBRE, publicado en enero, mostró que el índice acumuló en 2020 un crecimiento del $23,1 \%$, lo que supone una aceleración del

\footnotetext{
5 El IGP-M o índice general de precios de mercado, es un indicador de la variación de precios en la economía brasileña fundado en 1940 por la Fundación Getúlio Vargas (FGV). Es de cálculo mensual, pero se representa de forma acumulada de los últimos doce meses. Su resultado proviene de una media ponderada de otros índices: el índice de precios al por mayor (IPA-M), el índice de precios al consumidor (IPC-M) y el índice nacional de costo de la construcción (INCC-M). Suele ser el utilizado para la actualización de los contratos de alquiler, telefonía o luz.
}

crecimiento de los precios según este indicador de casi 16 puntos respecto al año anterior.

Según los datos del Banco Central de Brasil publicados en enero, en el conjunto del año 2020 el déficit en transacciones corrientes ascendió a 12.500 millones de dólares, equivalente al 0,9\% del PIB, frente al déficit del 2,7\% del PIB un año antes. Esta disminución en el déficit corriente se debió, principalmente, a la reducción en el déficit en la balanza de renta primaria y en el de la cuenta de servicios, además de la mejora del superávit comercial de bienes, que aumentó en 2.800 millones de dólares frente a 2019. Finalmente, las inversiones directas en el país (IDP) en el conjunto del ejercicio 2020 ascendieron a 34.200 millones de dólares, lo que supone el $2 \%$ del PIB, frente al $3,7 \%$ un año antes (69.200 millones de dólares).

\section{Conclusión}

El impacto de la COVID-19 sobre la economía brasileña revela una sensible desaceleración de la actividad en 2020 que ha afectado a todas las esferas de la economía. No obstante, la actuación del Gobierno habría permitido amortiguar los efectos del aislamiento social sobre la actividad y el empleo, de manera que el impacto sobre el crecimiento del PIB brasileño para 2020 se espera por debajo del ocurrido en otros países.

El año 2021 ha comenzado con optimismo, derivado del inicio de los procesos de vacunación en todo el mundo, incluido Brasil. Esta variable se ha revelado como fundamental en el desempeño a corto y medio plazo de las economías, a pesar de que mientras avanzan los planes de vacunación siguen siendo necesarias medidas de aislamiento locales y $\triangleright$ 
programas de ayuda por parte de las autoridades. De esta forma, el desempeño de la economía brasileña a lo largo de 2021 va a depender de cómo actúe el Gobierno, especialmente en lo que se refiere a la recuperación de la ayuda de emergencia, que ya se está debatiendo en el Congreso, así como en la reactivación de las reformas económicas pendientes y que tienen como objetivo mejorar el clima de negocio y la competitividad de la economía brasileña.

\section{Bibliografía}

Dong, E., Du, H., y Gardner, L. (2020). An interactive web-based dashboard to track COVID-19 in real time. The Lancet Infectious Diseases, 20(5), 533-534. https://doi.org/10.1016/S1473-3099(20) 30120-1

Fondo Monetario Internacional (2020). Brazil: 2020 Article IV Consultation-Press Release; Staff Report; and Statement by the Executive Director for Brazil. Country Report No. 2020/311. https:// www.imf.org/en/Publications/CR/lssues/2020/ 12/01/Brazil-2020-Article-IV-ConsultationPress-Release-Staff-Report-and-Statement-bythe-49927

Fundação Getulio Vargas-Instituto Brasilero Economia (2021). Estudios e Pesquisas. Sondagens e Indices de Confiança. https://portalibre.fgv.br/ estudos-e-pesquisas/indices-de-precos/indicede-confianca-empresarial

Gielow, I. (22 de enero de 2021). Crise derruba popularidade de Bolsonaro, aponta Datafolha. Folha de São Paulo. https://www1.folha.uol.com. br/poder/2021/01/crise-derruba-popularidade-de-bolsonaro-aponta-datafolha.shtml

Governo de São Paulo (2021). Conheça São Paulo. Números do Estado. https://www.saopaulo.sp. gov.br/conhecasp/

Instituto Brasilero de Geografia e Estadistica (2021). Sistema de Contas Nacionais Trimestrais.
Principais resultados. https://www.ibge.gov.br/ estatisticas/economicas/contas-nacionais/ 9300-contas-nacionais-trimestrais. html $?=\& \mathrm{t}=$ destaques

Instituto Brasilero de Geografia e Estadistica (2021). Sistema de Contas Nacionais Trimestrais. Publicações. $3^{\circ}$ trimestre 2020. Biblioteca. https://biblioteca.ibge.gov.br/visualizacao/periodicos/2121/cnt_2020_3tri.pdf

Instituto de Pesquisas Datafolha. Folha de São Paulo (25 y 26 de mayo de 2020). Avaliação do Governo Jair Bolsonaro. http://media.folha.uol.com. $\mathrm{br} /$ datafolha/2020/05/28/6b33e92c5fce7dcf946f577e614a7a1dagov.pdf

Instituto de Pesquisas Datafolha. Folha de São Paulo (11 y 12 de agosto de 2020). Avaliação do Governo Jair Bolsonaro. http://media.folha.uol.com. br/datafolha/2020/08/14/da7301f937d9224fe7ddf4cc81bcdf87ab.pdf

Instituto de Pesquisas Datafolha. Folha de São Paulo (20 y 21 de enero de 2021). Avaliação do Governo Jair Bolsonaro. http://media.folha.uol.com. br/datafolha/2021/01/26/b212555312706e10691 cf0ef9a8c981babpckt.pdf

Ministério da Cidadania (2021). Açoes e programas. Bolsa Familia. https://www.gov.br/cidadania/pt-br/acoes-e-programas/bolsa-familia

Ministério da Economia. Secretaria Especial de Fazenda (2020). Apresentação - Análise do Impacto Fiscal das Medidas de Enfrentamento ao Covid-19. https://www.gov.br/economia /pt-br/centrais-de-conteudo/apresentacoes/ 2020-12-22-transparencia_coletiva_covid.pdf/ view

Ministério da Saúde (2021). Painel de casos de doença pelo coronavírus 2019 (COVID-19) no Brasil pelo Painel Geral. https://covid.saude.gov. br/

Organización Mundial de la Salud (2021). WHO Coronavirus desease (COVID) Dashboard. https:// covid19.who.int/table 
Oficina Económica y Comercial de España en Brasilia

Organización para la Cooperación y el Desarrollo Económico (2020). Brazil. OECD Economic Outlook, 2020(2), 124-127. Preliminary Version (diciembre). https://doi.org/10.1787/888934217931

Pires, B., y Camporez, P. (28 de enero de 2021). Exclusivo: Planalto libera \$R 3bi em obras para 285 parlamentares em meio à eleição no Congresso.
Estadão. https://politica.estadao.com.br/noticias/ geral, planalto-libera-r-3-bi-em-obras-a-285-parlamentares-em-meio-a-disputa-no-congresso, 70003597254

PMI by IHS Markit (2021). Divulgações do PMI. https://www.markiteconomics.com/Public/ Release/PressReleases?language $=\mathrm{pt}$ 